Article

\title{
Economic Analysis and Environmental Impact Assessment of Heat Pump-Assisted Distillation in a Gas Fractionation Unit
}

\author{
Jisook Lee ${ }^{1,+} \mathbb{D}$, Yongho Son ${ }^{2,+}$, Kwang Soon Lee ${ }^{1}$ and Wangyun Won ${ }^{3, *}$ \\ 1 Department of Chemical \& Biomolecular Engineering, Sogang University, 35 Baekbeomro, Mapogu, \\ Seoul 04107, Korea; Jisook.Lee@schneider-electric.com (J.L.); kslee@sogang.ac.kr (K.S.L.) \\ 2 Department of Chemical \& Biomolecular Engineering, Korea Advanced Institute of Science and \\ Technology (KAIST), 291 Daehakro, Yuseonggu, Daejeon 34141, Korea; yhson87@kaist.ac.kr \\ 3 Department of Chemical Engineering, Changwon National University, 20 Changwondaehak-ro, Uichang-gu, \\ Changwon, Gyeongnam 51140, Korea \\ * Correspondence: wwon@changwon.ac.kr \\ + Equally contributed.
}

Received: 11 February 2019; Accepted: 27 February 2019; Published: 5 March 2019

\begin{abstract}
The depletion of fossil fuels and environmental pollution (e.g., greenhouse gas emissions) through the combustion of fossil fuels have stimulated studies on new technologies able to curtail the energy consumption of existing fractionation units. In this regard, heat pumps have garnered substantial attention due to their potential to improve the process energy efficiency. This study aims to provide extensive economic analysis and environmental impact assessment of the application of heat pumps under different conditions and scenarios. For this purpose, we first selected three important conditions: feed composition, plant capacity, and fuel price. Then, we performed a range of analyses to identify the major costs and environmental drivers. The economics and environmental impact of heat pump-assisted distillation was investigated and compared with those of conventional distillation.
\end{abstract}

Keywords: economics; life cycle; column; fractionation; gas separation; energy

\section{Introduction}

Distillation is one of the most important separation methods in the refinery, petrochemical, and gas process industries [1]. Due to the heat required for the reboiler and the heat removal required for the condenser, the conventional distillation columns clearly involve high-energy consumption. It is reported that distillation columns contribute to over $50 \%$ of the plant operating costs. Many research groups have proposed technologies to reduce the energy requirements of distillation.

Heat pumps are viable technologies to recover waste heat as valuable energy, thereby reducing the overall energy consumption. The low-quality energy released from the condenser can be upgraded to drive the reboiler using a heat pump [2]. Vapor recompression heat pumps (VRHPs), which enable substantial energy savings, have become the standard heat pump technology in distillation processes. Danziger [3] concluded that, for the separation of close boiling components, the energy saving of VRHPs is over $80 \%$ compared to conventional distillation systems. Fonyo and Benko [4] provided an orientation for process engineers on the application of heat pump systems to large industrial distillation columns. Their results showed that (1) larger heat loads and smaller process temperature differences $(\Delta \mathrm{T})$ provide shorter payback times, and (2) the absorption heat transformation cycles are considerable at large $\Delta \mathrm{T}$ values if other configurations are discarded. Diez et al. [5] demonstrated the economic feasibility of three different types of heat pumps for a C4 splitter (i.e., the distillation for the separation of a mixture of i-butane (iC4) and n-butane (nC4)). They showed that the heat pumps allowed a 
reduction of the energy cost of 33\% compared to the conventional distillation process. Fonyo et al. [6] presented a similar result in those of Diez et al. [5]. They showed that heat pumps are economically advantageous over conventional distillation in the case of a C4 splitter. Waheed et al. [7] developed enhanced VRHP models for a de-ethanizer to reduce the heat losses. The developed model led to considerable energy savings.

Some of the previous studies presented economic analyses of heat pumps, but these were limited to specific conditions. Moreover, no published literature exists on the environmental impact of heat pump-assisted distillation. For the practical implementation of heat pumps, economics and environmental impact should be extensively investigated. Accordingly, the purpose of this study was to perform a wide range of economic and environmental assessments for heat pumps to identify their key costs and environmental drivers. The analyses were conducted under various conditions, such as feed composition, plant capacity, and fuel price. The economics and environmental impact of the heat pump-assisted process are discussed in comparison with those of conventional distillation. Both C4 splitter and de-propanizer (for the separation of a mixture of propane (C3) and butanes (iC4 and nC4)) columns - the dominant energy contributors in a typical fractionation process-were considered in this study. A VRHP was considered for the representative heat pump-assisted system.

\section{Process Description}

Table 1 shows the product specifications and normal operating conditions of the distillation columns considered in this study. Further details on the process configuration are described in the following subsections.

Table 1. Feed conditions, operating conditions, and product specifications of the columns considered in this study.

\begin{tabular}{|c|c|c|c|}
\hline \multicolumn{2}{|c|}{ Operating Conditions } & C4 Splitter & De-Propanizer \\
\hline \multirow{3}{*}{ Feed conditions } & Flow rate $($ ton $/ \mathrm{h})$ & 214 & 7 \\
\hline & Temperature $\left({ }^{\circ} \mathrm{C}\right)$ & 55 & 109 \\
\hline & Pressure (Mpag) & 0.70 & 2.67 \\
\hline \multirow{6}{*}{ Feed composition (wt\%) } & Propane (C3) & 0.89 & 27.23 \\
\hline & Propylene (C3H6) & 0.06 & - \\
\hline & i-butane (iC4) & 76.48 & 23.70 \\
\hline & n-butane (nC4) & 22.57 & 40.96 \\
\hline & i-pentane (iC5) & - & 3.47 \\
\hline & n-pentane (nC5) & - & 4.64 \\
\hline \multirow{2}{*}{ Column operating pressure (Mpag) } & Top & 0.60 & 1.31 \\
\hline & Bottom & 0.66 & 1.42 \\
\hline \multirow{2}{*}{ Product specification (wt\%) } & Top & $93^{\mathrm{a}}$ & $96^{c}$ \\
\hline & Bottom & $95^{b}$ & $0.56^{c}$ \\
\hline \multirow{2}{*}{ Cooling water temperature $\left({ }^{\circ} \mathrm{C}\right)$} & Supply & 32 & 32 \\
\hline & Return & 42 & 42 \\
\hline \multicolumn{2}{|c|}{$\begin{array}{c}\text { Steam conditions } \\
\left({ }^{\circ} \mathrm{C} \text { at saturated pressure }\right)\end{array}$} & 147 & 147 \\
\hline
\end{tabular}

\subsection{C4 Splitter}

\subsubsection{Conventional Distillation}

Figure 1a shows the process flow diagram of the conventional C4 splitter (for stream information, see Table A1 in Supplementary Materials). In the C4 splitter (T-101), iC4 is separated from nC4 as the top product. The C4 splitter overhead vapor is sent to the condenser (E-101), where it is fully condensed using cooling water. The resulting liquid is then sent to the reflux drum (D-101), followed 
by the pump (P-101). The heating requirements for the reboiler (E-102) of the C4 splitter are satisfied by low-pressure steam.

\subsubsection{Heat Pump-Assisted Distillation}

Figure $1 \mathrm{~b}$ shows the process flow diagram of the heat pump-assisted $\mathrm{C} 4$ splitter (for stream information, see Table A2 in Supplementary Materials). Instead of using a steam reboiler and cooling water condenser, a heat pump is applied to meet the heating and cooling requirements. In the process, the overhead vapor is routed to the compressor (C-101) preceded by the knock-out drum (D-102), where liquid droplets are removed. The compressed vapor is then sent to the reboiler (E-102) to satisfy the reboiler duty. In the reboiler, the vapor is partly condensed. The effluent stream from the reboiler enters the flash drum (D-103), where the remaining vapor is further condensed using cooling water (E-103). Non-condensable gases included in the effluent stream are vented at D-103. The liquid from the flash drum is routed to the reflux drum (D-101) after being subcooled in the trim cooler (E-104). The vapor from the reflux drum is then sent to the knock-out drum via a suction heater (E-105). Part of the effluent liquid from the reflux drum (i.e., iC4) is pumped to the distillation column, while the remaining part of the effluent liquid is pumped downstream.

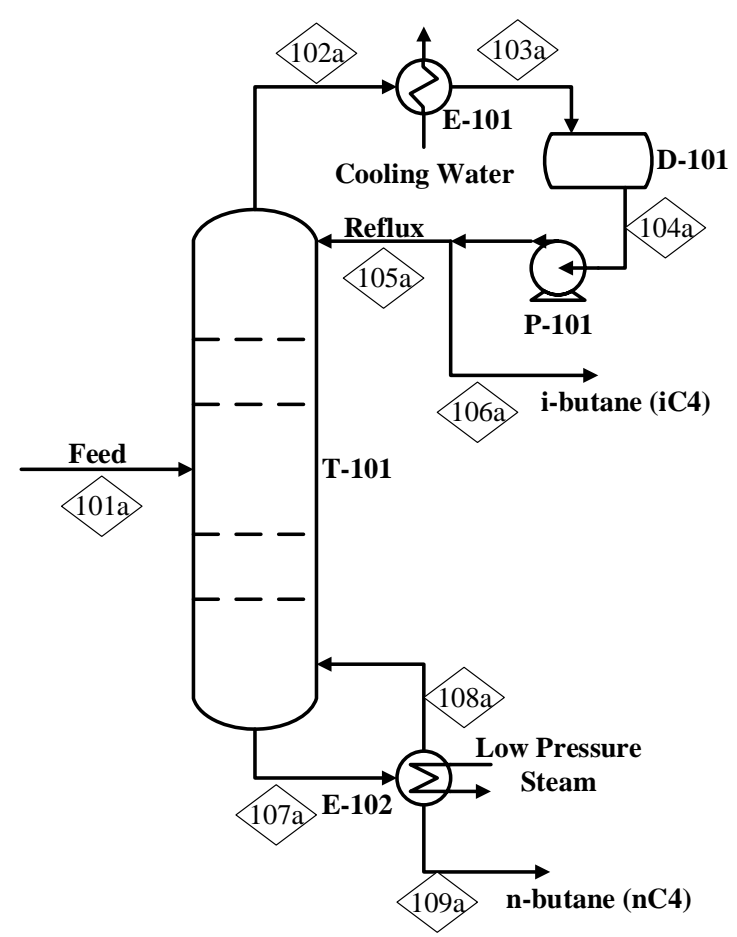

(a)

Figure 1. Cont. 


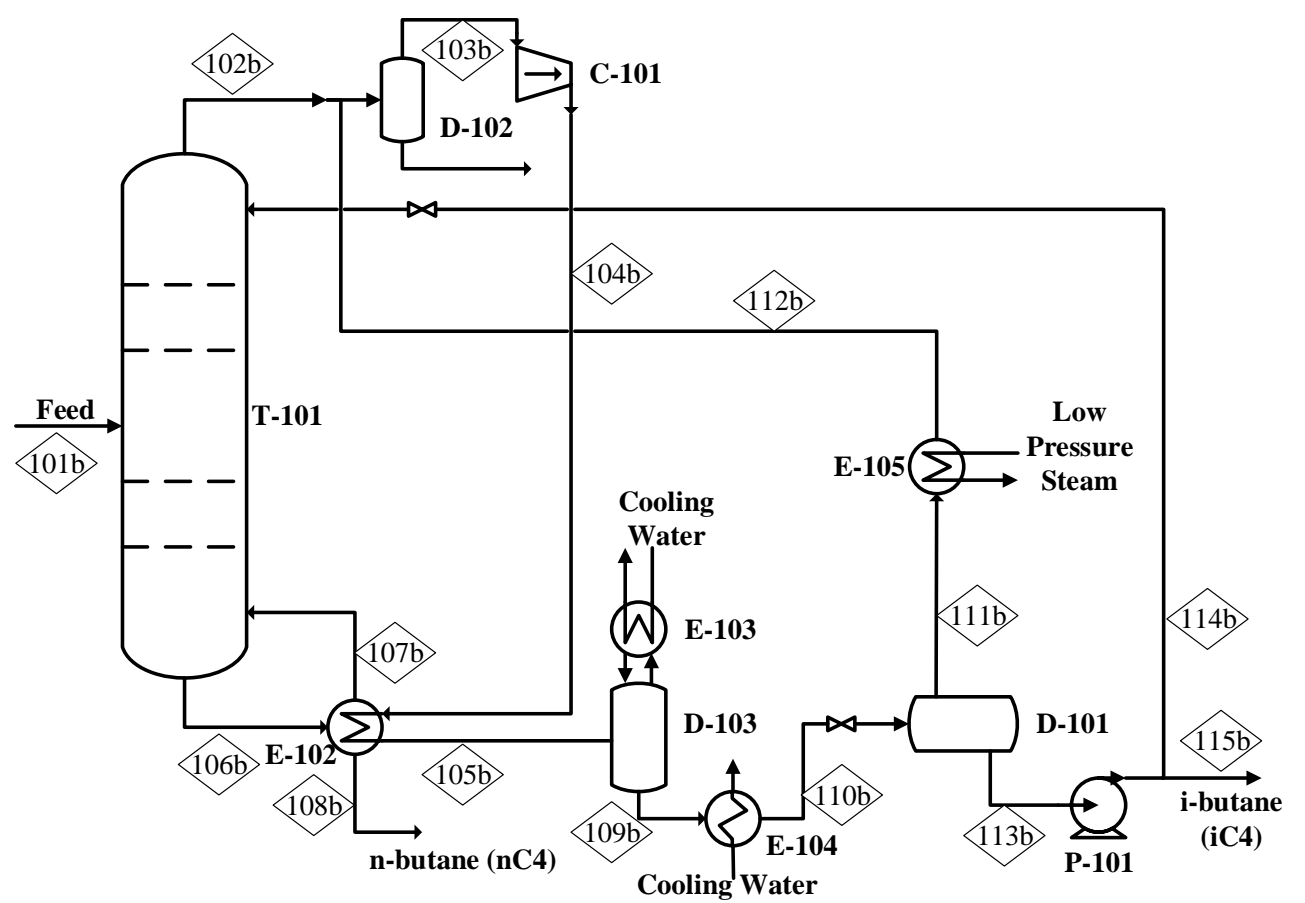

(b)

Figure 1. Process flow diagram for the $\mathrm{C} 4$ splitter in (a) conventional and (b) heat pump-assisted distillation.

\subsection{De-Propanizer}

\subsubsection{Conventional Distillation}

Figure 2a shows the process flow diagram of the conventional de-propanizer (for stream information, see Table A3 in Supplementary Materials). The C3 and butanes are separated by the de-propanizer, with $\mathrm{C} 3$ as the overhead product. The overhead vapor of the de-propanizer is collected in the reflux drum (D-201) after being condensed with cooling water (E-201). Part of the condensate is sent back to the column via a reflux pump (P-201), while the remaining part of the condensate is withdrawn as the liquid C3 product. Steam is supplied to the reboiler (E-202) to meet the heating requirements.

\subsubsection{Heat Pump-Assisted Distillation}

Figure $2 \mathrm{~b}$ shows the process flow diagram of the heat pump-assisted de-propanizer (for stream information, see Table A4 in Supplementary Materials). A heat pump is used to reduce the utility consumption (cooling water and steam). After removing the liquid droplets in the knock-out drum (D-202), the de-propanizer overhead vapor is compressed (C-201) and then sent to the reboiler (E-202). Part of the reboiler duty is satisfied by the compressed overhead vapor, while the remaining part of the reboiler duty is met by the low-pressure steam (E-203). After condensation in the reboiler (E-202), the overhead stream is subcooled in the trim cooler (E-204). The resulting liquid is then collected in the reflux drum (D-201). Part of the liquid is returned to the distillation column (T-201), while the remaining part of the liquid is routed to a downstream process. 


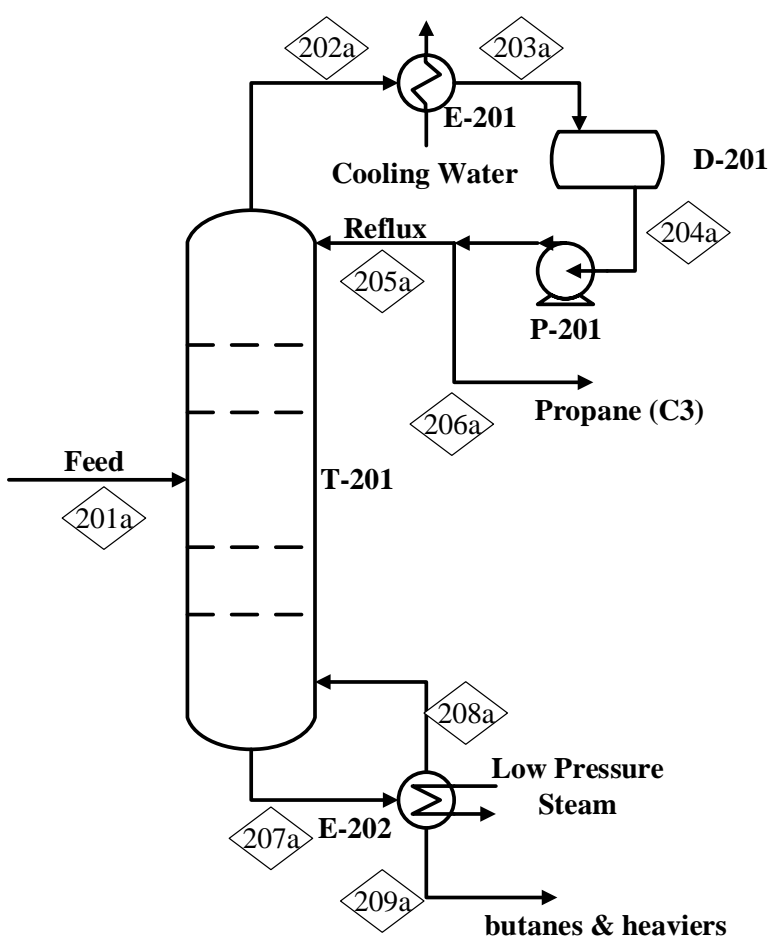

(a)

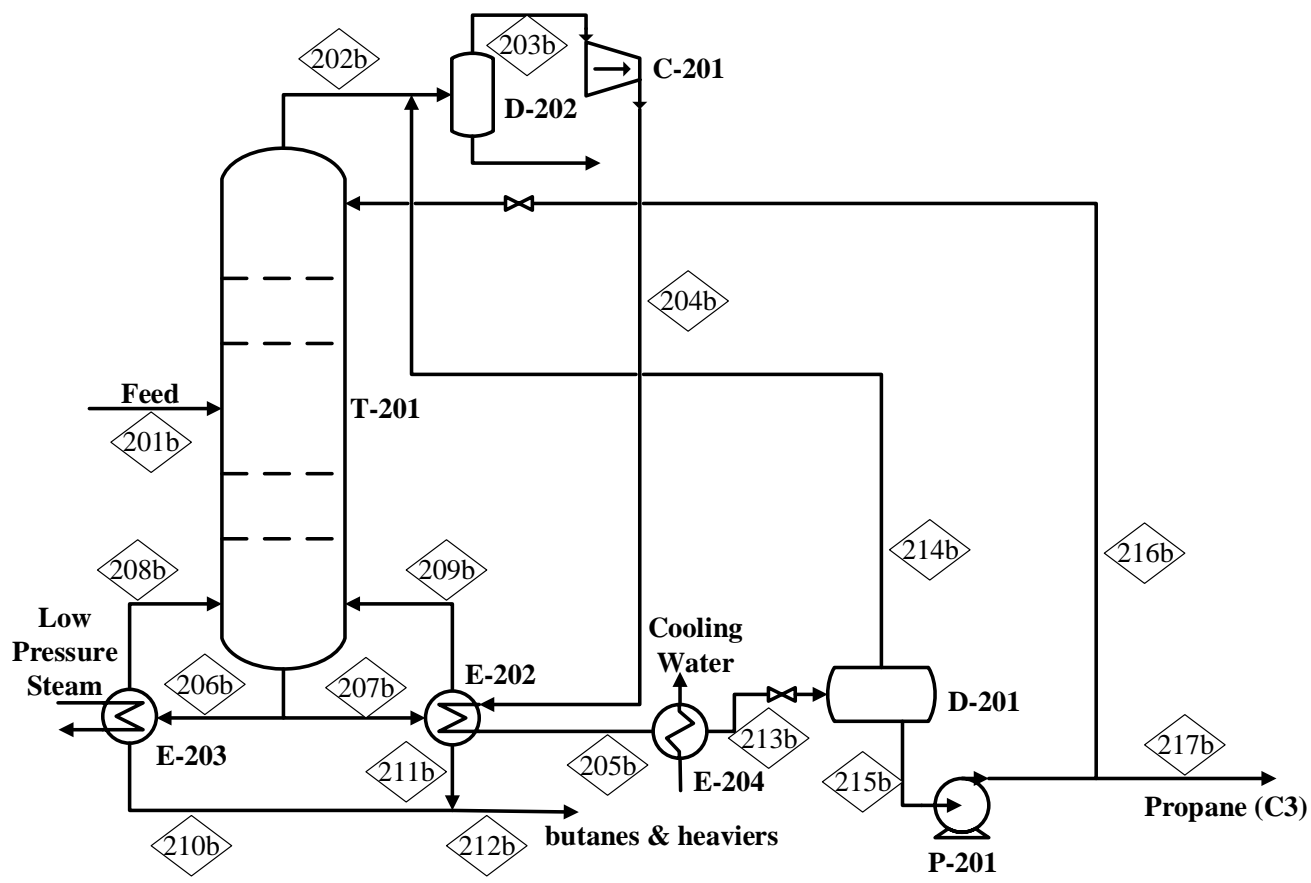

(b)

Figure 2. Process flow diagram for the de-propanizer in (a) conventional and (b) heat pump-assisted distillation. 


\section{Process Simulation}

\subsection{Basis}

We developed a process model using PRO/II ${ }^{\circledR}$ (SimSci by Schneider Electric, USA) [8], which provides a rigorous distillation module based on the product specifications and operating conditions given in Table 1. The Peng-Robins equation was used to calculate the thermodynamic properties. The liquid density was calculated using the API method, and the transport properties based on the pure component properties provided by $\mathrm{PRO} / \mathrm{II}^{\circledR}$ [8]. A process model for heat pump-assisted distillation was developed by adjusting the distillation meant for conventional distillation, based on the following assumptions:

1. The column operating conditions, such as the pressure, temperature, reflux rate, reboiler duty, and product specifications, for conventional and heat pumped distillation processes are exactly the same.

2. A single stage compressor without a subsequent cooler is included to compress the column overhead vapor.

3. The compression ratio and outlet temperature of the compressor are determined such that (1) the temperature between the hot fluid inlet and cold fluid outlet is higher than $10{ }^{\circ} \mathrm{C}$ in the reboiler, and (2) the outlet temperature of the compressor does not exceed the mechanical limit (i.e., $\left.130{ }^{\circ} \mathrm{C}\right)$.

\subsection{Process Conditions}

Using the process model described in the previous section, we investigated the impact of varying important process conditions on the economics of conventional and heat pump-assisted distillations. Table 2 shows the process conditions considered in this study. The lower and upper bounds of the process conditions were set according to values reported in the literature. First, we considered the feed composition, which can vary with the time depending on the operation of upstream processes. The feed composition has a significant effect on the design and operation of a fractionation process, such as the equipment size and utility consumption. Second, we considered the plant capacity. In general, the desired plant capacity may change depending on the propane or butane requirements (e.g., changes in the required amount of mixed refrigerants) or market conditions (changes in the market price of liquefied petroleum gas). Third, we considered the fuel price, which is a prime determinant of the utility cost. The fuel price has fluctuated significantly over the past decades. The lower and upper bounds of the fuel price in Table 2 account for a certain price volatility, as reported by the US Department of Energy.

Table 2. Important process conditions.

\begin{tabular}{cccc}
\hline \multicolumn{2}{c}{ Process Conditions } & Lower Bound & Upper Bound \\
\hline \multirow{2}{*}{ Feed composition (weight basis) } & C4 splitter & iC4:nC4=1:1.5 & iC4:nC4=10:1 \\
& De-propanizer & C3:C4s $=1: 4$ & C3:C4s=4:1 \\
\hline \multirow{2}{*}{ Plant capacity } & C4 splitter & $10 \%$ & $300 \%$ \\
& De-propanizer & $10 \%$ & $1000 \%$ \\
\hline \multirow{2}{*}{ Fuel price } & & $3.1 \$ / \mathrm{GJ}$ & $16 \$ / \mathrm{GJ}$ \\
\hline
\end{tabular}

\section{Economic Analysis}

\subsection{Capital and Operating Costs}

Based on the mass and energy balances obtained from the process simulation, we estimated the equipment cost of the column, heat exchanger, compressor, drum, and pump [9,10]. For the estimation of the equipment cost, a cost-capacity algorithm was used [11]. All equipment costs were adjusted to 
a common basis year (2016) using the Chemical Engineering Plant Cost Index [12]. For more details on the equipment sizing and cost estimation, the readers are referred to Sections B and C in the Supplementary Materials.

The operating costs were estimated based on the utility consumption (i.e., steam, cooling water, and electricity) calculated for the process model [13]. To estimate the operating costs, the process uptime was assumed to be $8400 \mathrm{~h}$ per year, in accordance with industrial practice [14]. For more details on the estimation of the operating costs, the readers are referred to Section D in the Supplementary Materials.

\subsection{Performance Metrics}

To quantitatively analyze the process performance, we considered three different metrics. First, we considered the percentage of energy savings, which was calculated using the following equation [7]:

$$
\text { Energy savings }(\%)=\frac{\mathrm{OC}_{\mathrm{C}}-\mathrm{OC}_{\mathrm{H}}}{\mathrm{OC}_{\mathrm{C}}} \times 100
$$

where $\mathrm{OC}_{\mathrm{C}}$ and $\mathrm{OC}_{\mathrm{H}}$ represent the operating costs of the conventional and heat pump-assisted distillations, respectively. The percentage of energy savings indicates how much the operating costs are reduced by introducing a heat pump in the distillation process relative to the conventional scheme.

Compared to conventional distillation, heat pump-assisted distillation inevitably leads to an increase in the capital cost because it requires additional equipment, such as a compressor and knock-out drum. The second metric considered in this study was the payback time [15], which is defined as the period of time required to recover the funds expended to upgrade a conventional distillation to a heat pump-assisted distillation or to reach the break-even point [7]:

$$
\text { Payback time }(\mathrm{yr})=\frac{\mathrm{CC}_{\mathrm{H}}-\mathrm{CC}_{\mathrm{C}}}{\mathrm{OC}_{\mathrm{C}}-\mathrm{OC}_{\mathrm{H}}}
$$

where $\mathrm{CC}_{\mathrm{C}}$ and $\mathrm{CC}_{\mathrm{H}}$ refer to the capital cost of the conventional and heat pump-assisted distillations, respectively.

Finally, we considered the total annual cost, defined as the sum of the annualized capital cost and operating cost $[16,17]$.

$$
\mathrm{TAC}_{\mathrm{i}}=\mathrm{CRF} \times \mathrm{CC}_{\mathrm{i}}+\mathrm{OC}_{\mathrm{i}} \text { where } \mathrm{i}=\mathrm{C} \text { or } \mathrm{H}
$$

In the above, TAC is the total annual cost, and the subscripts $\mathrm{C}$ and $\mathrm{H}$ refer to the conventional and heat pump-assisted distillations, respectively. The CRF multiplied by the capital cost considers only the value actually dissipated at the present time by depreciation of the capital initially invested for the equipment, such that

$$
\mathrm{CRF}=\frac{\mathrm{r}(1+\mathrm{r})^{\mathrm{n}_{\mathrm{j}}}}{(1+\mathrm{r})^{\mathrm{n}_{\mathrm{j}}}-1}
$$

where $r$ represents an interest rate and $n_{i}$ is the lifetime of equipment $j$ [18].

\section{Environmental Impact Assessment Using Life Cycle Assessment (LCA)}

\subsection{System Boundaries and Goal of LCA}

LCA is a methodology that evaluates the environmental impact of processes and products by considering their life cycle from cradle to grave. The basic framework of the LCA methodology can be found in the literature as per the International Standard Organization [19]. The LCA framework recommends following basic steps, starting from the definition of goal and system boundaries. The primary goal of LCA in this study was to determine whether the heat pump-assisted distillation was environmentally more favorable than conventional distillation. The system boundary of gate-to-gate instead of cradle-to-grave is sufficient in this study, because the upstream and downstream processes and product specification are identical in both schemes [20]. 
Since the main environmental concern in this study was $\mathrm{CO}_{2}$ emissions, conventional distillation and heat pump-assisted distillation were compared with respect to their global warming impact (GWI). The global warming impact is a single metric for global warming calculated as the accumulated greenhouse gas (GHG) emissions in $\mathrm{CO}_{2}$-equivalents $\left(\mathrm{CO}_{2}\right.$-eq.) by weighting the global warming potential (GWP), which accounts for the capability of the GHG to absorb radiation [20].

\subsection{Functional Units for the Investigated Processes}

The functional units (FUs) in LCA define the functions of the investigated processes, thus becoming a comparison basis [20]. The main functions of the conventional distillation and heat pump-assisted distillation of the C4 splitter and de-propanizer are the separation of $\mathrm{iC} 4$ and $\mathrm{C} 3$ from each feed stream. To quantify the main function, we chose both top and bottom products satisfying the product specifications as references for the functions 'conventional C4 splitter' (i.e., 1.0-ton vapor of $93 \%$ iC4 and 1.0-ton liquid of $95 \% \mathrm{nC} 4=\mathrm{FU}_{\mathrm{C} 4 \text { splitter }}$ ) and 'conventional de-propanizer' (i.e., 1.0-ton vapor of $96 \% \mathrm{C} 3$ and 1.0-ton liquid of $0.56 \% \mathrm{C} 3=\mathrm{FU}_{\text {de-propanizer }}$ ). In this study, the environmental impact of global warming is provided in $\mathrm{kg} \mathrm{CO}_{2}$-eq./FU (for details, see Table E1 in the Supplementary Materials).

The heat pump-assisted distillation involves more pieces of equipment, such as a compressor and heat exchanger, compared to conventional distillation. However, the additional equipment is not included in this LCA analysis because the environmental impact of the equipment assembly in the chemical industry is negligible [21].

\section{Results}

\subsection{Evaluation of the Capital and Operating Costs}

Figure 3 shows the results of the economic evaluation of conventional and heat pump-assisted distillations. The annualized capital cost is lower than the annual operating cost for all systems. The annualized capital cost and annual operating cost account for $8-33 \%$ and $67-92 \%$ of the total annual cost, respectively.

In conventional distillation, the cost of the column and steam account for a large portion of the annualized capital cost and annual operating cost. In the heat pump-assisted distillation, the cost of the compressor is about $30-40 \%$ of the annualized capital cost, and the cost of electricity is about $60-90 \%$ of the annual operating cost.

In the C4 splitter, the annualized capital cost for heat pump-assisted distillation is higher than for the conventional distillation, whereas the annual operating cost of the conventional distillation is higher than that of the heat pump-assisted distillation, as shown in Figure 3a,b. The main reasons behind the increase in the annualized capital cost and operating cost are the cost of the compressor and steam, respectively, in the heat pump-assisted distillation and conventional distillation. The total annual cost of the heat pump-assisted distillation $\left(11.69 \times 10^{6} \$ / \mathrm{yr}\right)$ is reduced to about $47 \%$ compared to that of the conventional distillation $\left(24.77 \times 10^{6} \$ / \mathrm{yr}\right)$, led by steam cost reduction.

On the other hand, the total annual cost of the heat pump-assisted distillation is $22 \%$ higher than that of the conventional distillation with a de-propanizer. The cost of the compressor and electricity leads to increased annualized capital costs and annual operating costs, as shown in Figure $3 c, d$, respectively.

The cost of the pump did not vary with the process configuration in this study. The cost of the drums increased in the heat pump-assisted distillation by increasing the number of required drums in the process, as shown in Figures $1 b$ and $2 b$. In Figure $3 b$, the heat exchanger cost for the heat pump-assisted distillation with the $\mathrm{C} 4$ splitter is higher than that for the conventional distillation, due to an increase of the total required heat transfer area; however, the total required heat transfer area of the heat pump-assisted distillation is lower than that for the conventional distillation. Consequently, the heat exchanger cost is lower for the system with the de-propanizer column. 


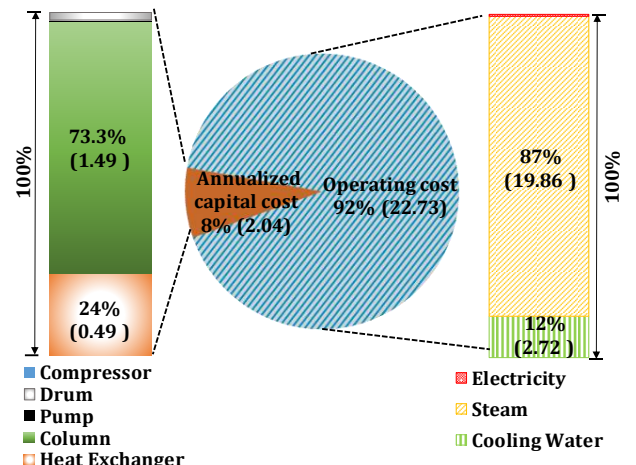

(a)

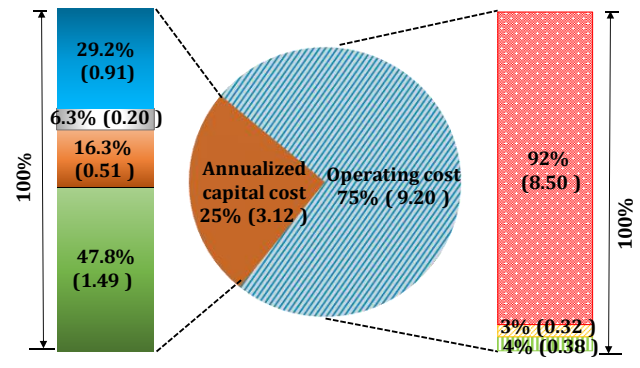

(b)

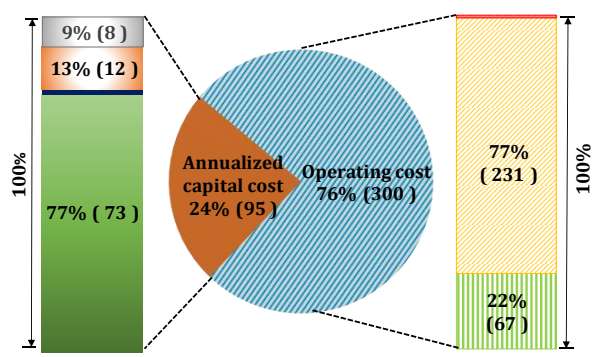

(c)

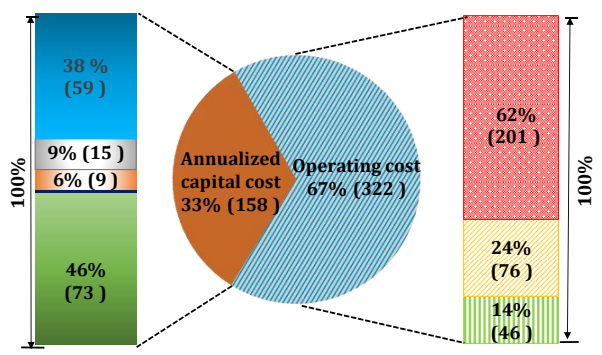

(d)

Figure 3. Cost contributions. The numbers in parentheses denote the costs $\left(10^{6} \$ / \mathrm{yr}\right.$ and $10^{3} \$ / \mathrm{yr}$ for the C4 splitter and de-propanizer, respectively): (a) Conventional C4 splitter; (b) heat pump-assisted C4 splitter; (c) conventional de-propanizer; and (d) heat pump-assisted de-propanizer. 


\subsection{Sensitivity Analysis}

We evaluated the parameter effects on the economic feasibility by performing a sensitivity analysis. We calculated the total annual cost, percentage of energy savings of the heat pump-assisted distillation compared to conventional distillation, and the payback time by varying the feed composition, plant capacity, and fuel price within a specific range. The results are presented in Figures 4 and 5.

As shown in Figure 4, the total annual cost depends on the feed composition, plant capacity, and fuel price. In the C4 splitter, the total annual cost of the conventional distillation is higher than that of the heat pump-assisted distillation for all cases. The total annual cost tends to decrease by increasing the iC4 composition in the feed, as shown in Figure 4a,d. By increasing the iC4 composition, the key ratio in the column stage defined as Equation (5) [8] increases. Consequently, the separation is improved, reducing the equipment costs and annual operating cost.

$$
\text { Key ratio }=\frac{\text { Light key mole fraction in liquid phase }}{\text { Heavy key mole fraction in liquid phase }}
$$

where light key refers to the iC4 component and heavy key to the nC4 component.

However, in the case of a feed composition ratio of 1:1.5 (Figure 4a), the total annual cost is increased compared to the 1:3 feed case. In the latter, the separation is improved a little bit, but more heat duty is required to vaporize the iC4 component from the liquid feed to the top product and to cool more products. At feed ratios above 1:3, such a separation effect starts to become more and more prominent.

With the de-propanizer, the total annual cost of the heat pump-assisted distillation is higher than in the conventional distillation for all cases. The cost of the compressor and electricity leads to an increase of the total annual cost, as shown in Figure $4 \mathrm{~g}-1$. The total annual cost of conventional distillation tends to decrease with the increasing C 3 composition in the feed, as shown in Figure 4g. By increasing the $\mathrm{C} 3$ composition in the feed, the key ratio increases, resulting in improved separation. Consequently, the annual operating cost decreases.

Similarly, in the C4 splitter, when the feed composition ratio is 1:2.5 (Figure 4g), the total annual cost increases compared to the 1:4 feed ratio case. More heat duty is required to vaporize the C3 component from the liquid feed to the top product to cool more products. Above 1:2.5 feed ratios, this separation effect becomes more apparent.

In contrast, by increasing the C 3 composition in the feed in the heat pump-assisted distillation, the top vapor product increases leading to increases in the compressor size and consumption of electricity. On the other hand, the consumption of steam is reduced, because the steam reboiler duty (E-203 in Figure $2 \mathrm{~b}$ ) is replaced by compression heat. Therefore, the total annual cost of the heat pump-assisted distillation does not change significantly with variations in the feed composition in this study, as shown in Figure 4j.

As seen in Figure $4 \mathrm{~b}, \mathrm{e}, \mathrm{h}, \mathrm{k}$ by increasing the plant capacity, the total annual costs increase. However, the total annual cost does not increase in proportion to the plant capacity change as the annualized capital cost does not increase proportionally either. For example, in Figure $4 \mathrm{~b}$, the plant capacity changes from $100 \%$ to $300 \%$, but the total annual cost increases only about four-fold. In Figure $4 \mathrm{k}$, the plant capacity changes from $100 \%$ to $1000 \%$, but the total annual cost increases about eight-fold.

With the increasing fuel price, the total annual costs also increase in Figure $4 \mathrm{c}, \mathrm{f}, \mathrm{i}, 1$ due to the increased utility costs. The total annual cost of the conventional distillation is more sensitive to fuel price fluctuations. As the fuel price changes from $6.5 \$ / G J$ to $3.1 \$ / G J$, the total annual cost decreases by $43 \%$ and $33 \%$ for the conventional distillation with a $\mathrm{C} 4$ splitter and de-propanizer, respectively. In the case of a fuel price increase from 6.5 \$ GJ to 12.5 \$ GJ, the total annual cost increases by $77 \%$ and $59 \%$ for the conventional distillation with a $C 4$ splitter and de-propanizer, respectively. In contrast, the decrease/increase rates are $21 \% / 38 \%$ and $22 \% / 38 \%$ for the heat pump-assisted distillation with a C4 splitter and de-propanizer, respectively. 


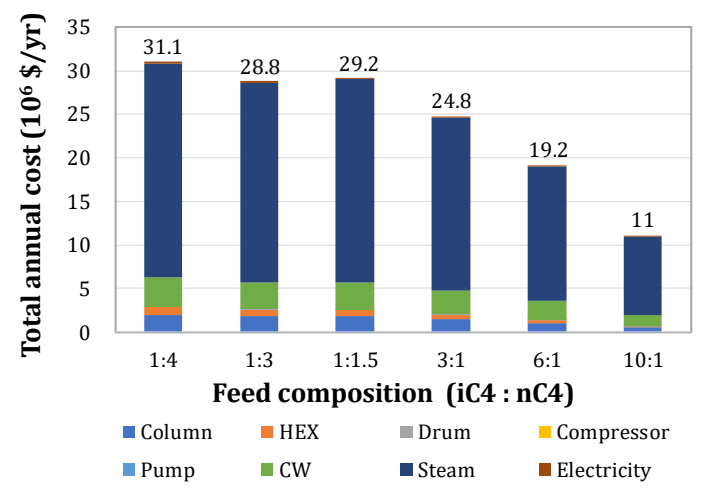

(a)

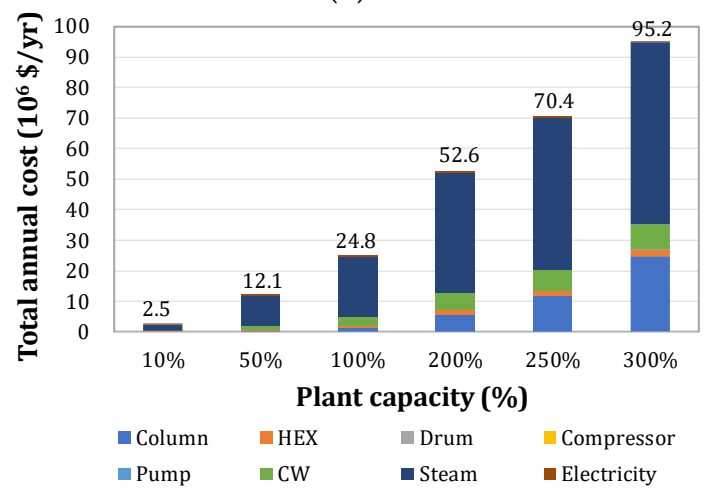

(b)

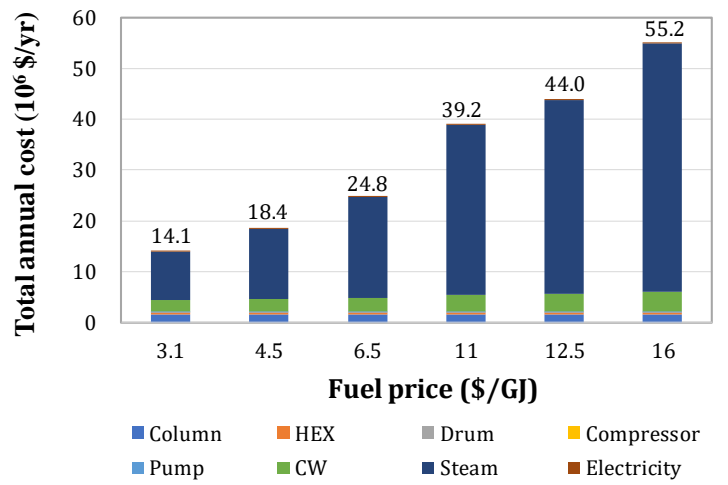

(c)

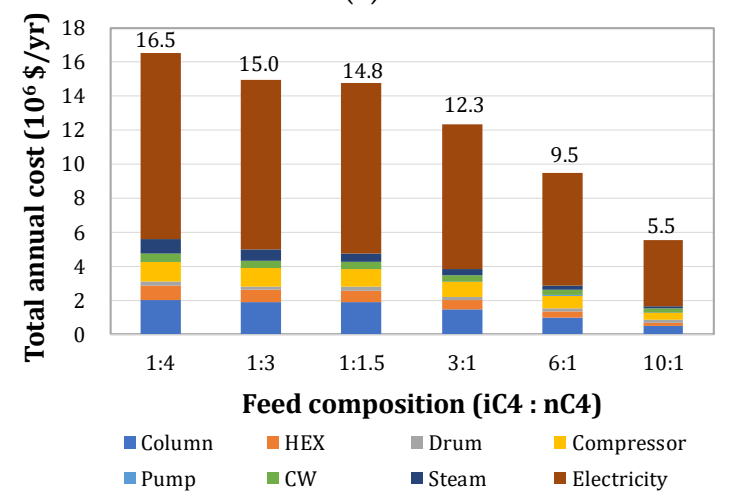

(d)

Figure 4. Cont. 


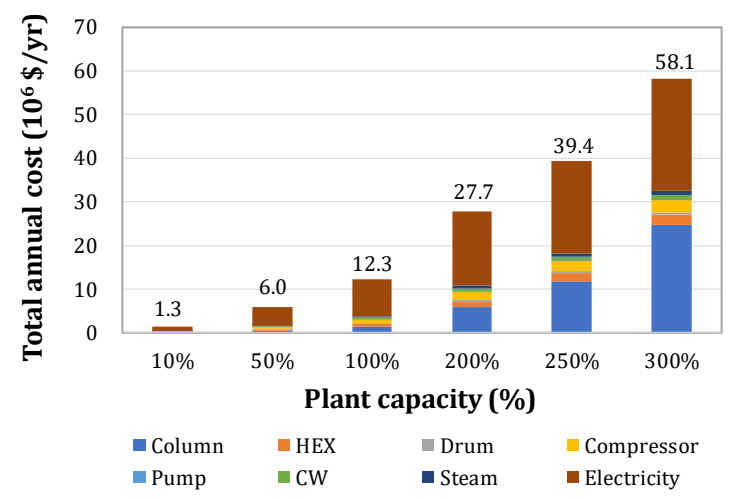

(e)

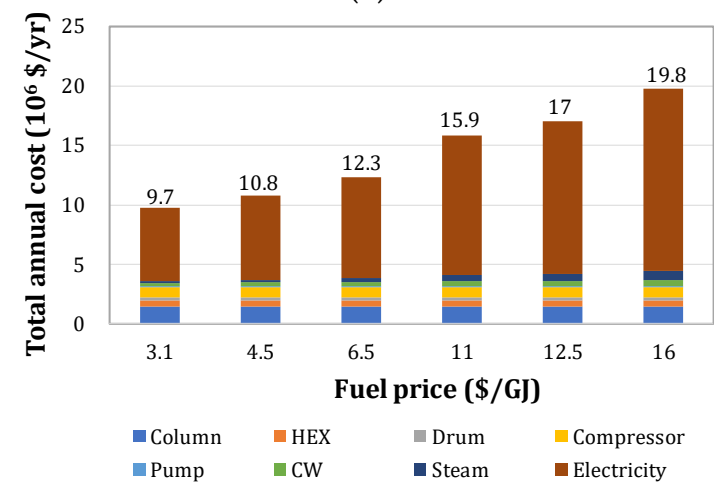

(f)

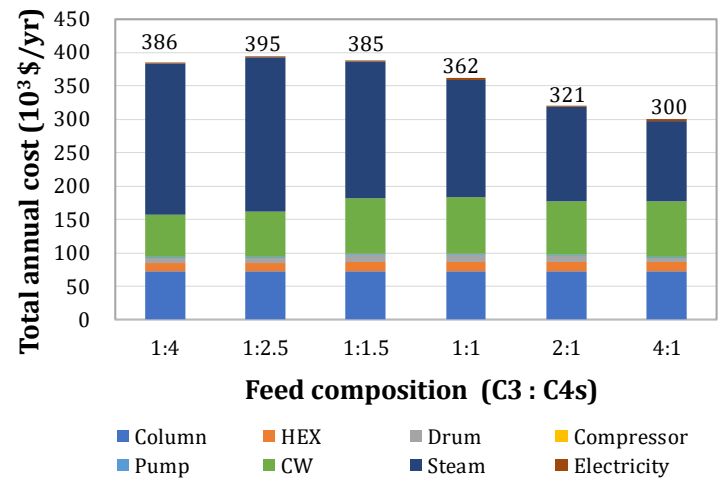

(g)

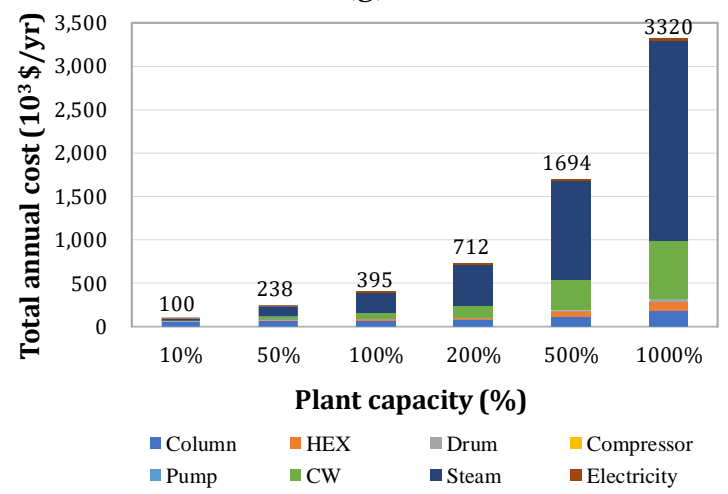

(h)

Figure 4. Cont. 


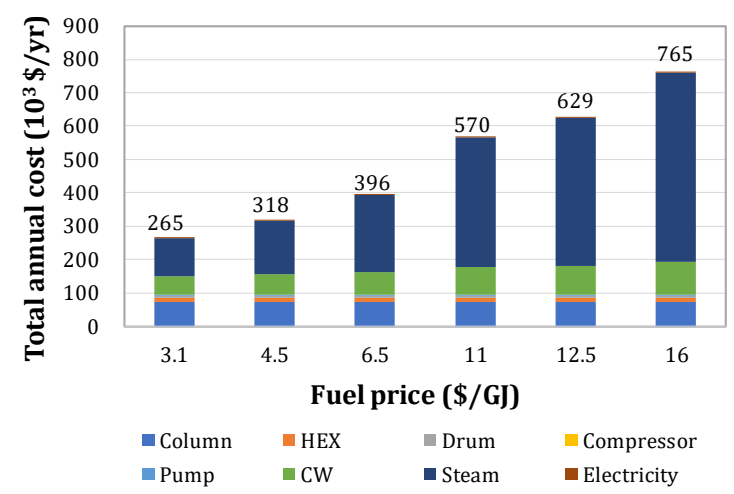

(i)

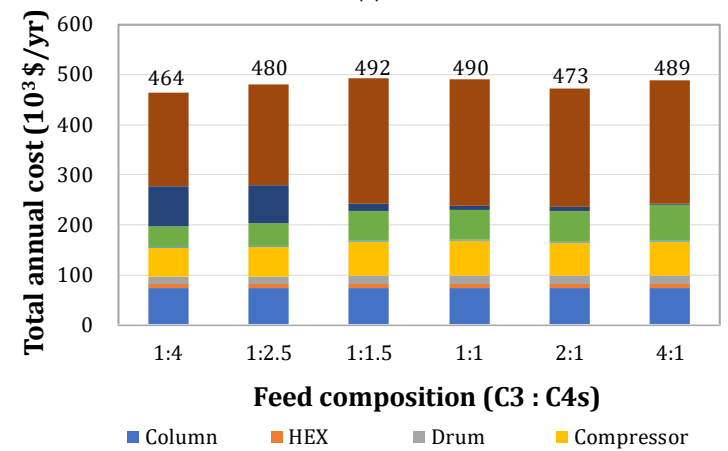
$\because$ Pump $\quad \because \mathrm{CW}$
- Steam
- Electricity

(j)

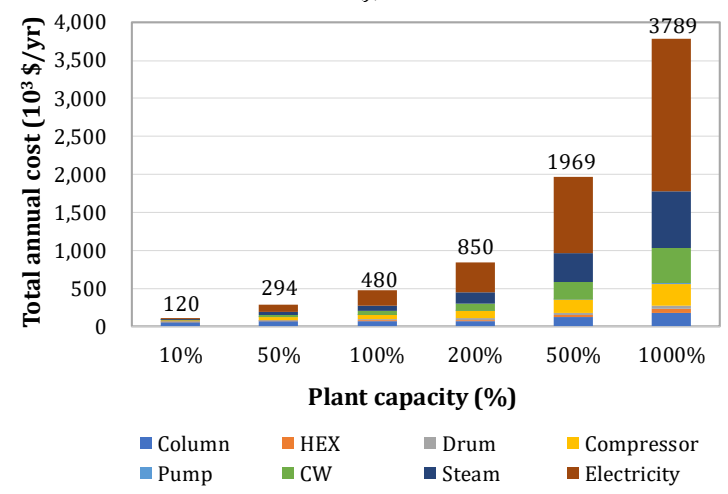

(k)

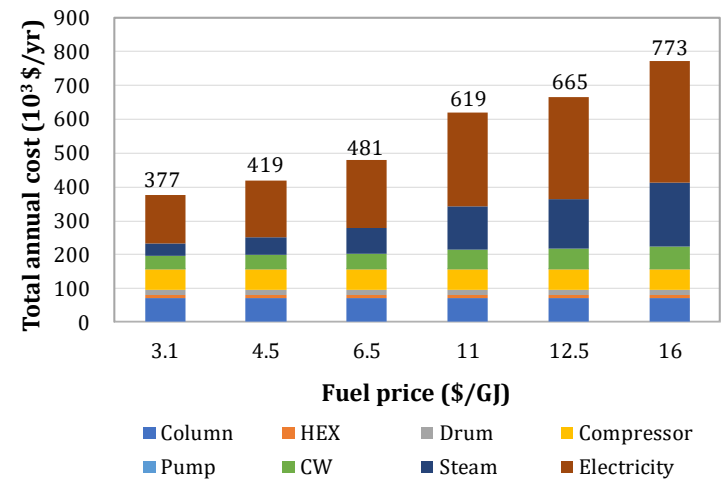

(1)

Figure 4. Sensitivity of the total annual cost to the process conditions (feed composition, plant capacity, and fuel price): (a-c) Conventional C4 splitter; $(\mathbf{d}-\mathbf{f})$ heat pump-assisted C4 splitter; (g-i) conventional de-propanizer; and $(\mathbf{j}-\mathbf{l})$ heat pump-assisted de-propanizer. 
In Figure 5a-c, the percentage of energy savings in the heat pump-assisted distillation of the $\mathrm{C} 4$ splitter compared to the conventional distillation is over $50 \%$, and the payback time is less than one year, except for the case where the fuel price is $3.1 \$ / G J$. The energy saving value increases with the fuel price, as shown in Figure 5c.

With the de-propanizer, the percentage of energy savings in the heat pump-assisted distillation has a positive value only at fuel prices higher than 11 \$ /GJ, as indicated in Figure $5 d-f$.

Based on the evaluation results in Figure $5 c, f$ the fluctuation of fuel prices is a considerable parameter for the study of economic feasibility. With the increasing fuel price, the energy saving value increases and the investment can be recovered in a short time for both the $\mathrm{C} 4$ splitter and de-propanizer systems.

The energy saving value and payback time does not change significantly depending on the composition of $\mathrm{iC} 4$ in the feed stream for the $\mathrm{C} 4$ splitter (Figure 5a).

The percentage of energy savings maintains a similar value upon varying the plant capacity in Figure $5 b, e$, because the annual operating costs increase proportionally with the plant capacity.

The variation of the $\mathrm{C} 3$ composition in the feed stream influences the percentage of energy savings in the de-propanizer (Figure 5d). However, the heat pump-assisted distillation still does not show economic feasibility upon varying the feed composition and plant capacity, as shown in Figure 5d,e.

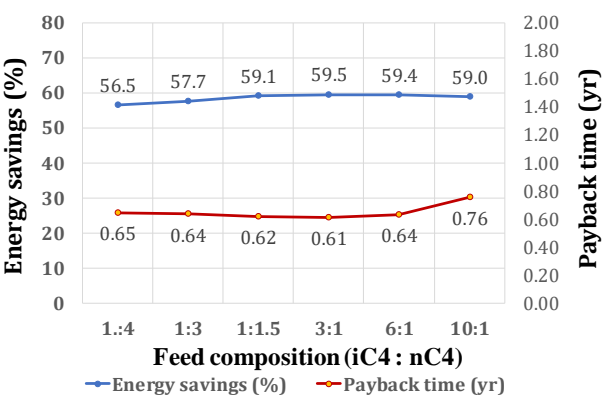

(a)

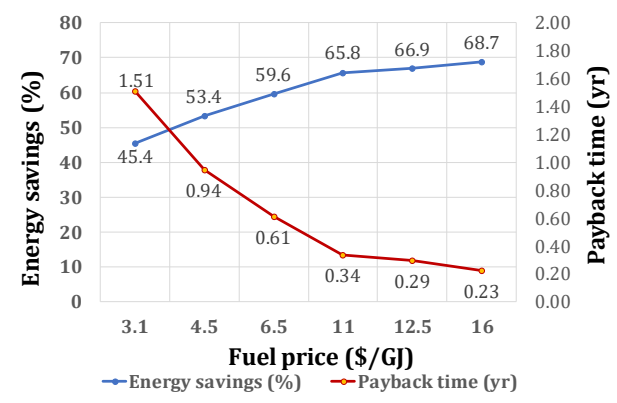

(c)

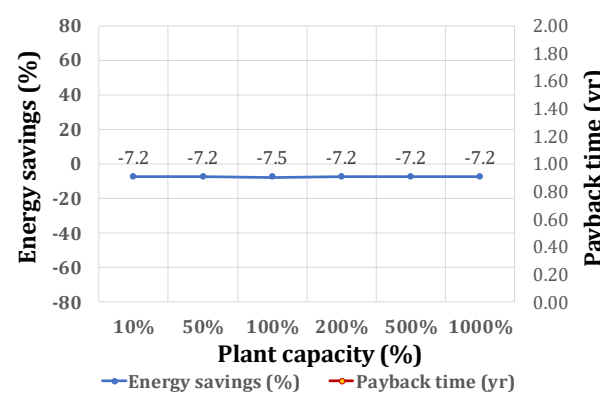

(e)

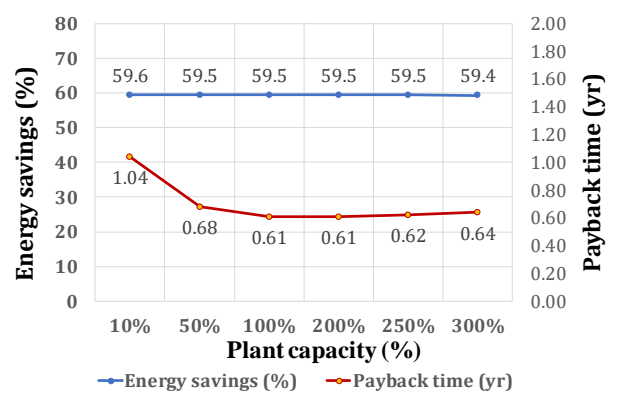

(b)

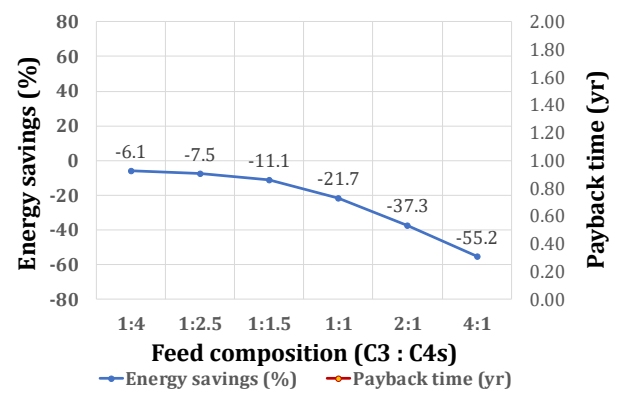

(d)

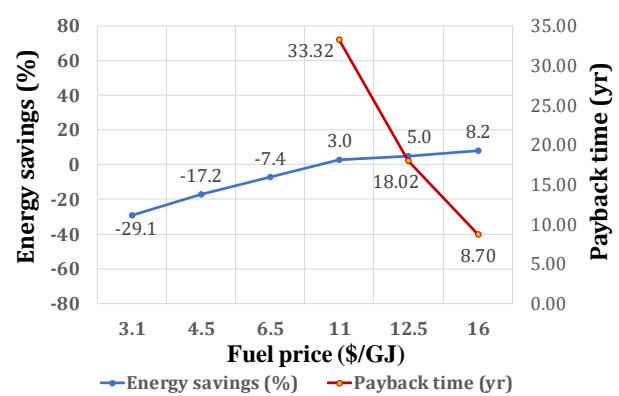

(f)

Figure 5. Sensitivity of energy savings and payback time to the process conditions (feed composition, plant capacity, and fuel price): (a-c) Heat pump-assisted C4 splitter; and (d-f) heat pump-assisted de-propanizer. 
The capital cost, which was not optimized in this study, may be reduced by adjusting the operating conditions, such as the temperature, pressure, and/or reflux ratio. Moreover, the electricity price can vary depending on the location. To investigate the impact of the above two parameters on the total annual cost and payback time, we performed a sensitivity analysis, whose results are provided in Figure 6.

As shown in Figure $6 a, c$, the total annual cost varies with the electricity price and capital cost. The total annual cost is more sensitive to electricity cost variations, as shown in Figure 6a,c. The total annual cost decreased by $0.69 \%$ and $0.55 \%$ for the $\mathrm{C} 4$ splitter and de-propanizer, respectively, with an electricity price drop of $1 \%$, while the total annual cost decreased by $0.25 \%$ and $0.34 \%$ for the C 4 splitter and de-propanizer upon a $1 \%$ reduction of the capital cost.

Figure $6 \mathrm{~b}, \mathrm{~d}$ illustrate the effect of variations in the electricity price and capital cost on the payback time. In Figure $6 b$, the effect of the variation of the electricity price and capital cost reduction on the payback time is almost the same. The payback time for the heat pump-assisted de-propanizer is converted from a meaningless negative value to a positive value, as indicated by the red dot line (around $0.115 \$ / \mathrm{kWh}$ ) in Figure $6 \mathrm{~d}$. If the electricity cost is higher than the red dot line value, the payback is impossible despite any deductions on the capital cost.

If the capital cost and electricity price are reduced by $5 \%$ with respect to the presently assumed ones (base case), the total annual cost for the heat pump-assisted C4 splitter is reduced to $11.69 \times 10^{6} \$ / y r$, leading to a decrease in payback time from 7.3 to 6.7 months.

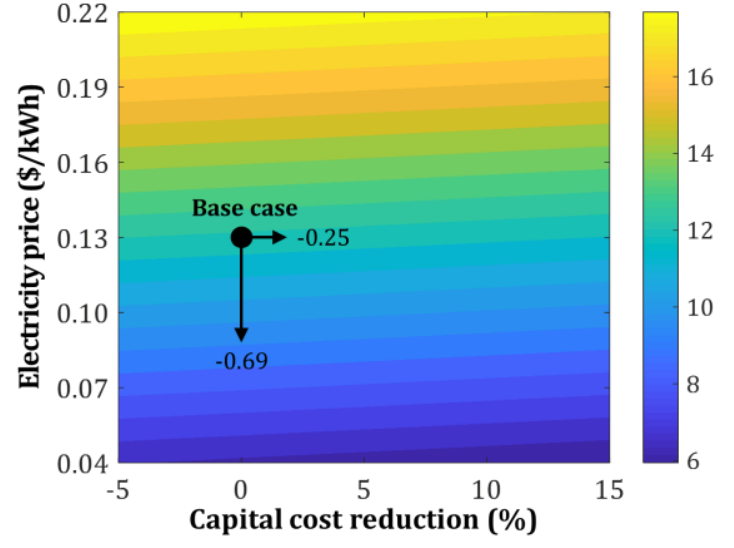

(a)

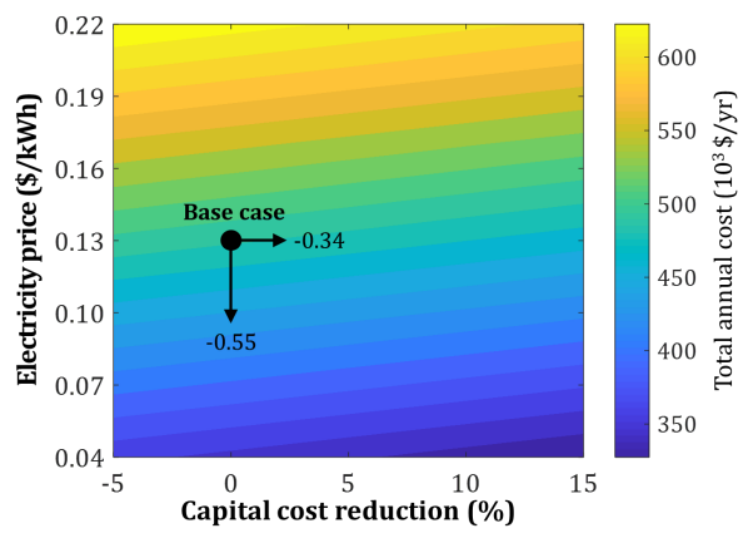

(c)

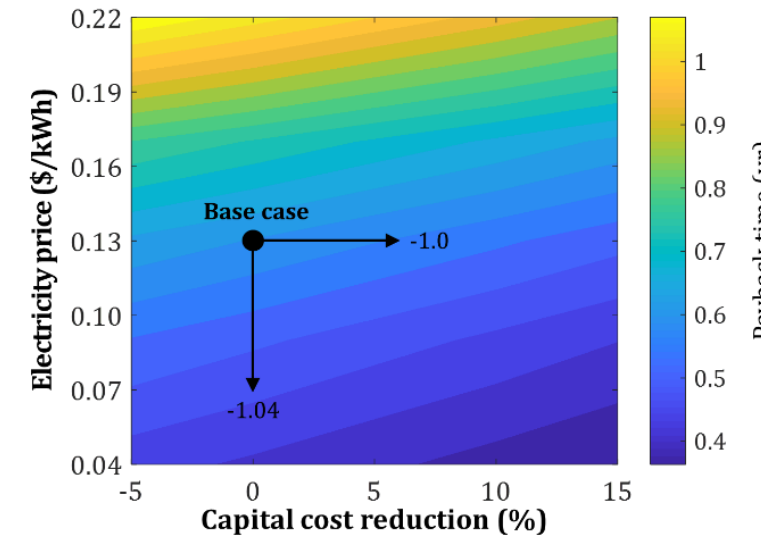

(b)

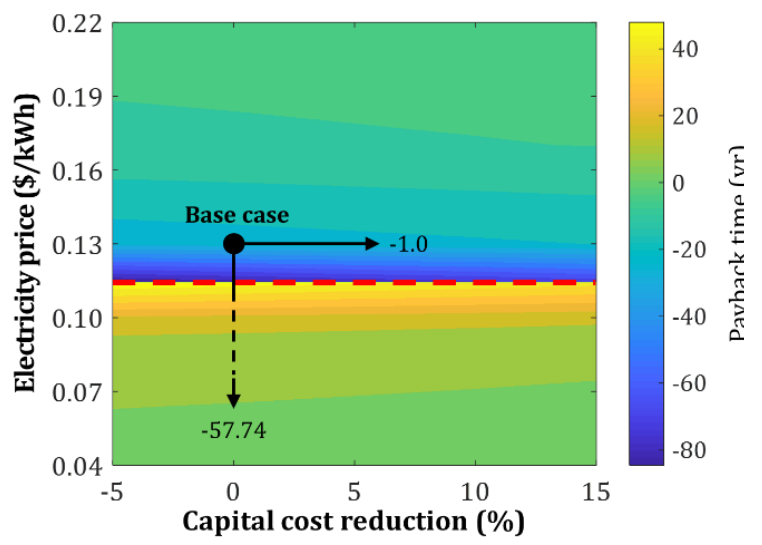

(d)

Figure 6. Sensitivity of the total annual cost and payback time to economic parameters: $(\mathbf{a}, \mathbf{b})$ Heat pump-assisted C4 splitter and (c,d) heat pump-assisted de-propanizer. The numbers represent the total annual cost variation (\%) or payback time variation (\%) due to a $1 \%$ change in a parameter. 


\subsection{LCA Results and Discussion}

The gate-to-gate impact on global warming was assessed for the functional units $\mathrm{FU}_{\mathrm{C} 4 \text { splitter }}$ and $\mathrm{FU}_{\mathrm{de} \text {-propanizer }}$ for the $\mathrm{C} 4$ splitter and de-propanizer, respectively. Figure 7 shows the global warming impact of the $\mathrm{C} 4$ splitter and de-propanizer in conventional and heat pump-assisted distillations. In both the C4 splitter and de-propanizer cases, the largest contributor to the total GHG emissions of the conventional distillation is the steam supplied to the reboiler (E-102 and E-202). By switching to an alternative configuration using a heat pump, the GHG emissions can be reduced by $81 \%$ (C4 splitter) and 32\% (de-propanizer) compared to those of conventional distillation. Major GHG emission reductions originate from lower steam consumption, which is substituted by the electricity consumption of the heat pump (C-101 and C-201). For the de-propanizer, the heat pump-assisted column has a smaller reduction effect than the $\mathrm{C} 4$ splitter, which can be explained by the temperature difference between the vapor to be compressed and the reboiler to be heated. The temperature difference in the de-propanizer is approximately $50{ }^{\circ} \mathrm{C}$ compared to the $15^{\circ} \mathrm{C}$ of the $\mathrm{C} 4$ splitter, which leads to more energy consumption of both electricity and steam to provide the required reboiler heat duty for the de-propanizer.

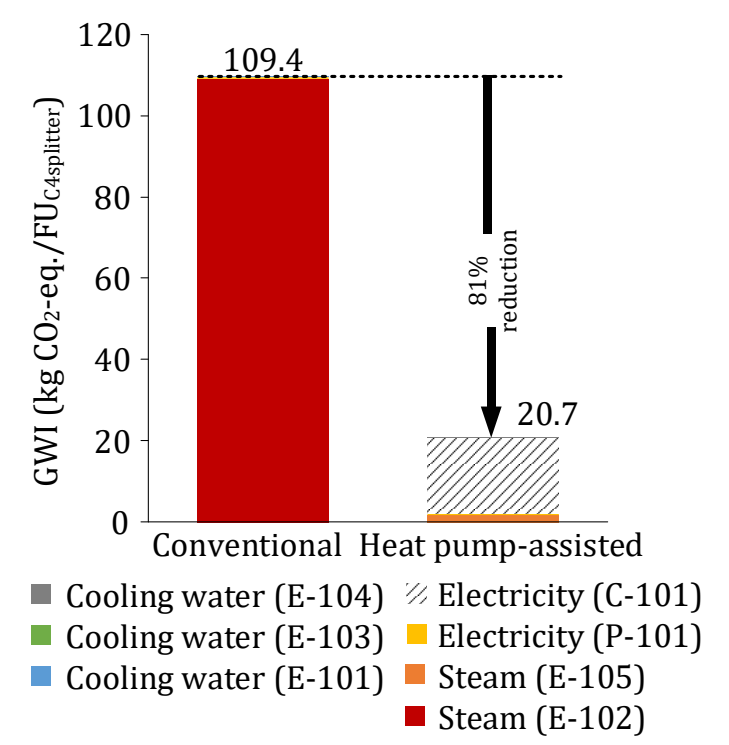

(a)

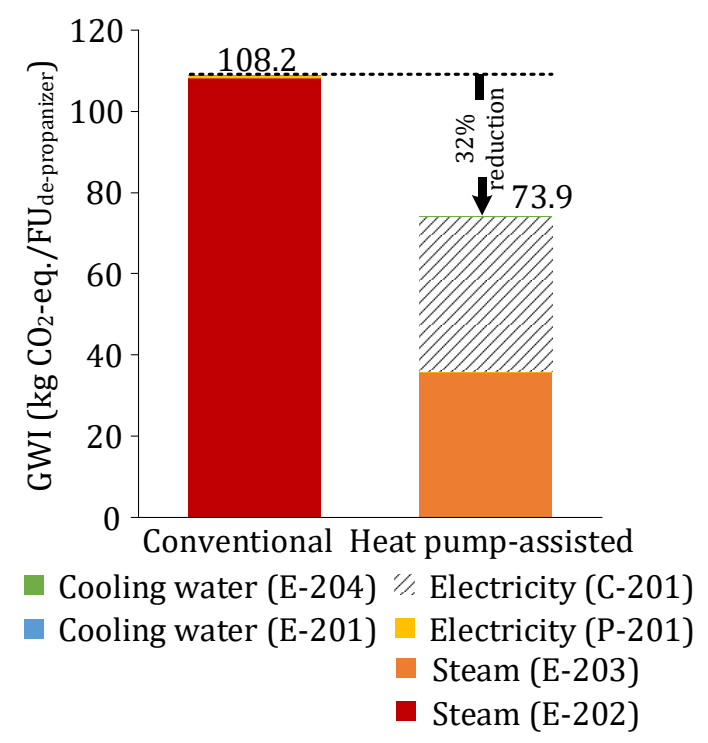

(b)

Figure 7. GWI (Global warming impact) in $\mathrm{kg} \mathrm{CO}_{2}$-equivalents $\left(\mathrm{kg} \mathrm{CO}_{2}\right.$-eq.) per functional unit (FU) for (a) a C4 splitter in conventional distillation (left) and heat pump-assisted distillation (right), and (b) a de-propanizer in conventional distillation (left) and heat pump-assisted distillation (right).

Figure 8 shows the effects of plant capacity and feed composition on the $\mathrm{CO}_{2}$ reduction by introducing a heat pump in the $\mathrm{C} 4$ splitter and de-propanizer. $\mathrm{CO}_{2}$ reduction is defined as the percentage difference of GWI between conventional distillation and heat pump-assisted distillation over the GWI of conventional distillation: it is the quantitative environmental advantage against global warming of switching to a heat pump configuration. Similar to the energy saving analysis in Figure 5, no effect of the plant capacity was observed on the $\mathrm{CO}_{2}$ reduction in the case of heap pump-assisted distillation. On the other hand, the feed composition exhibited a different behavior. In both the C4 splitter and de-propanizer, the heavier component in the feed increased as well as the GWI of the conventional distillation due to a larger reboiler heat duty. Accordingly, the GWI of the heat pump-assisted column increased. For the $\mathrm{C} 4$-splitter, the $\mathrm{CO}_{2}$ reduction was almost constant over the considered range of feed compositions. On the other hand, the $\mathrm{CO}_{2}$ reduction for the de-propanizer reached its maximum at a feed composition of 1:1.5. 


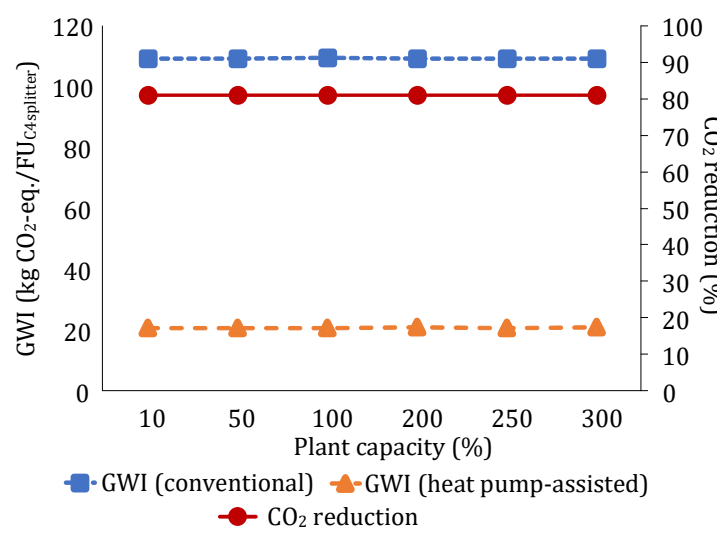

(a)

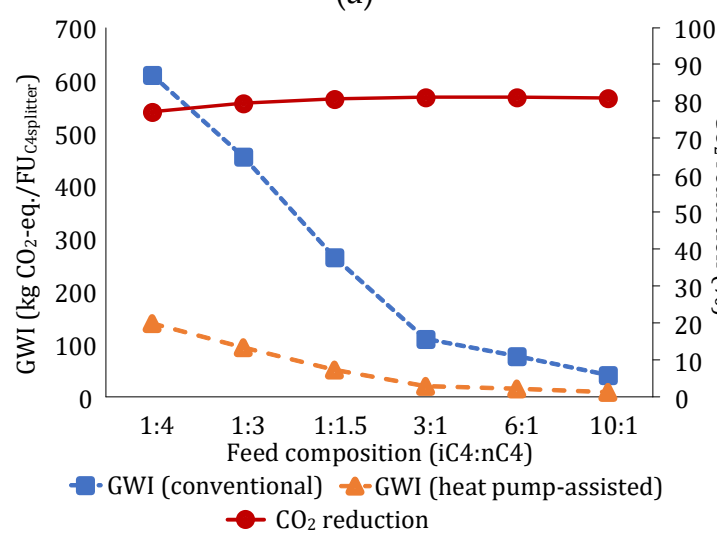

(c)

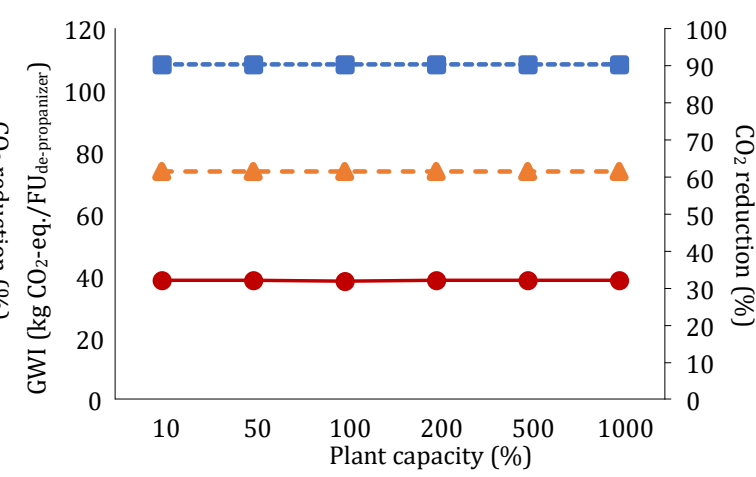

-GWI (conventional) -GWI (heat pump-assisted) $\rightarrow \mathrm{CO}_{2}$ reduction

(b)

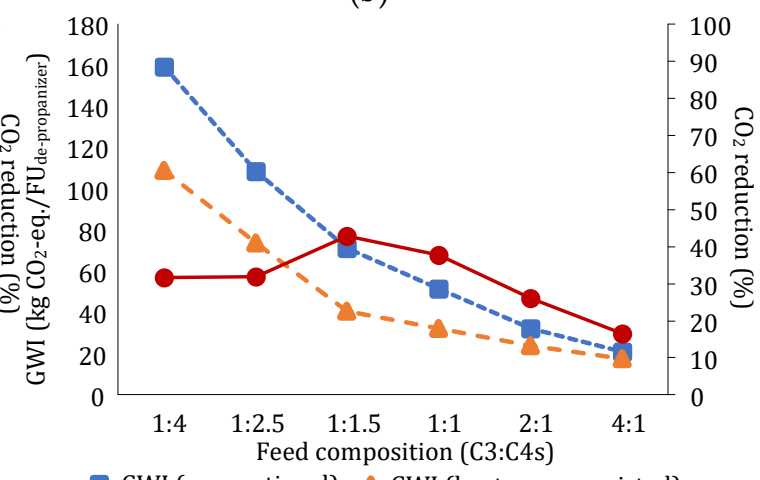

-GWI (conventional) -GWI (heat pump-assisted)

$\rightarrow \mathrm{CO}_{2}$ reduction

(d)

Figure 8. GWI (global warming impact) in $\mathrm{kg} \mathrm{CO}$-equivalents ( $\mathrm{kg} \mathrm{CO}_{2}$-eq.) per functional unit (FU). (a) and (b) effect of the plant capacity on the GWI for the C4 splitter and the de-propanizer in conventional distillations, respectively and (c,d) effect of the feed composition on the GWI for the C4 splitter and the de-propanizer in heat pump-assisted distillations, respectively.

Figure 9 shows the effect of the GWI of electricity on the $\mathrm{CO}_{2}$ reduction for the heat pump-assisted distillation compared to that for conventional distillation to gauge any potential effect of the electricity. Since electricity will likely be generated from various sources following technology advances in the near future or at the sites where the distillation columns are operated, this sensitivity analysis can provide useful information. As the electricity is generated from cleaner sources, such as renewable energy instead of fossil-based resources, the GWI of electricity decreases. The cleanest electricity is generated from wind energy, which is approximately 0.0002 [22]. The GWI of electricity from other sources is tabulated in the Supplementary Materials. Both the C4 splitter and de-propanizer can reduce more their $\mathrm{CO}_{2}$ emissions as the GWI of electricity is lowered (i.e., cleaner electricity). However, the increment of the $\mathrm{CO}_{2}$ reduction effect with respect to the unit decrement of GWI is two times higher in the case of the de-propanizer, about $3.4 \mathrm{CO}_{2}$ reduction (\%) w.r.t. $0.01 \mathrm{GWI}$ of electricity for the de-propanizer compared to $1.7 \mathrm{CO}_{2}$ reduction (\%) w.r.t. $0.01 \mathrm{GWI}$ of electricity for the $\mathrm{C} 4$ splitter, as determined for coal-based electricity. Since the $\mathrm{CO}_{2}$ emission by electricity usage in the heat pump-assisted distillation is larger in the case of the de-propanizer, the $\mathrm{CO}_{2}$ reduction effect achieved by eliminating the electricity contribution for a lower GWI is greater than in the case of the C4 splitter. 


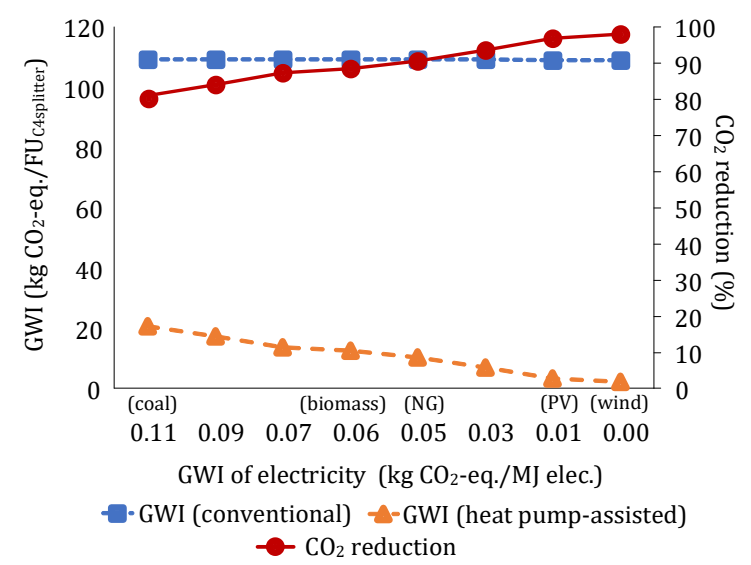

(a)

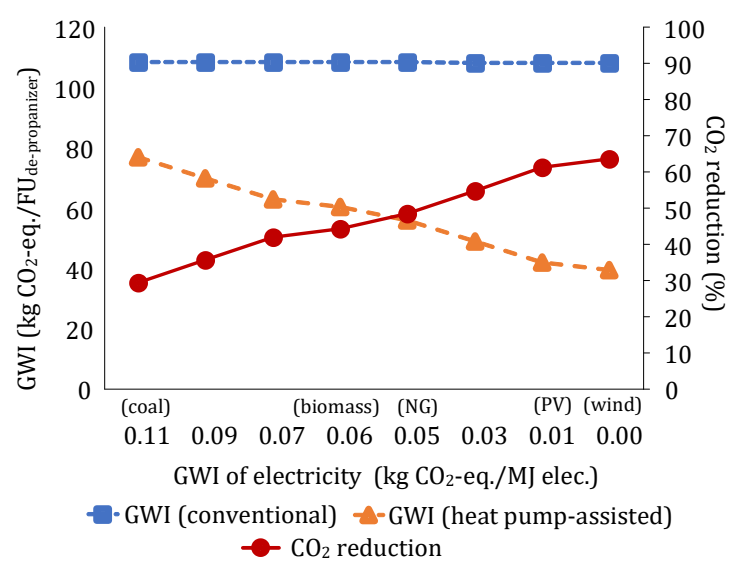

(b)

Figure 9. GWI (global warming impact) in $\mathrm{kg} \mathrm{CO}_{2}$-equivalents ( $\mathrm{kg} \mathrm{CO}_{2}$-eq.) per functional unit (FU). Effect of the GWI of electricity for the (a) C4 splitter and (b) de-propanizer in conventional and heat pump-assisted distillations.

\section{Conclusions}

In this study, we simulated conventional and heat pump-assisted distillations with either a C4 splitter or a de-propanizer by considering various situations. Based on the simulation results, an evaluation of the annualized capital cost and annual operating cost was performed, and the economic feasibility was reviewed for both distillation systems.

From the results of the sensitivity analysis, we found that the energy saving value and payback time for heat pump-assisted distillation depend on feed composition, plant capacity, and fuel price. Similarly to the results from other reports, heat pump-assisted distillation is economically feasible in the case of a C4 splitter process [5,6], while, except in cases of high fuel prices or very low electricity prices, heat pump-assisted distillation is not suitable with a de-propanizer column.

In addition, we evaluated the parameters closely related to the economic feasibility through sensitivity analysis. The fluctuation of fuel or electricity prices was found to be a considerable parameter on the economic feasibility in this particular study.

It is noteworthy that, although heat pump-assisted distillation is not feasible economically except under certain conditions, the environmental impact of the heat pump with respect to global warming is positive for both the $\mathrm{C} 4$ splitter and de-propanizer columns. Moreover, the use of cleaner electricity can greatly reduce the $\mathrm{CO}_{2}$ emissions of heat pump-assisted distillation processes.

Supplementary Materials: The following are available online at http:/ /www.mdpi.com/1996-1073/12/5/852/s1, Table A1: Process stream information (from flowsheet in Figure 1a), Table A2: Process stream information (from flowsheet in Figure 1b), Table A3: Process stream information (from flowsheet in Figure 2a), Table A4: Process stream information (from flowsheet in Figure 2b), Table B1: Sizing results for the column base cases, Table B2: Overall heat transfer coefficients, Table B3: Areas of the heat exchangers used in this study, Table B4: Sizing results for the drums used in this study, Table B5: Power requirements of the compressor, Table B6: Capacity of the pump, Table C1: Equations for the purchased equipment cost, CE, and installation factors, Table C2: Equipment costs for conventional distillation, Table C3: Equipment costs for heat pump-assisted distillation, Table D1: Utility cost coefficient and unit price of utility, Table D2: Utility costs for conventional distillation, Table D3: Utility costs for heat pump-assisted distillation, Table E1: Utility costs for heat pump-assisted distillation.

Author Contributions: Conceptualization, J.L. and W.W.; Methodology, J.L. and Y.S.; Investigation, J.L. and Y.S.; Writing-Original Draft Preparation, J.L. and Y.S.; Writing-Review \& Editing, K.S.L. and W.W.; Supervision, K.S.L. and W.W.; Project Administration, W.W.; Funding Acquisition, W.W.

Funding: This research was supported by C1 Gas Refinery Program through the National Research Foundation of Korea (NRF) funded by the Ministry of Science, ICT \& Future Planning (2015M3D3A1A01064929).

Conflicts of Interest: The authors declare no conflict of interest. 


\section{References}

1. Won, W.; Lee, S.K.; Choi, K.; Kwon, Y. Current trends for the floating liquefied natural gas (FLNG) technologies. Korean J. Chem. Eng. 2014, 31, 732-743. [CrossRef]

2. Kiss, A.A. Advanced Distillation Technologies; John Wiley \& Sons, Inc.: Hoboken, NJ, USA, 2013.

3. Danziger, R. Distillation columns with vapor recompression. Chem. Eng. Prog. 1979, 75, 58-64.

4. Fonyo, Z.; Benko, N. Comparison of various heat pump assisted distillation configurations. Chem. Eng. Res. Des. 1998, 76, 348-360. [CrossRef]

5. Diez, E.; Langston, P.; Ovejero, G.; Romero, M.D. Economic feasibility of heat pumps in distillation to reduce energy use. Appl. Therm. Eng. 2009, 29, 1216-1223. [CrossRef]

6. Fonyo, Z.; Kurrat, R.; Rippin, D.W.T.; Meszaros, I. Comparative analysis of various heat pump scheme applied to C4-splitters. Comput. Chem. Eng. 1995, 19, s1-s6. [CrossRef]

7. Waheed, M.A.; Oni, A.O.; Adejuyigbe, S.B.; Adewumi, B.A.; Fadare, D.A. Performance enhancement of vapor recompression heat pump. Appl. Energy 2014, 114, 69-79. [CrossRef]

8. SimSci, PRO/II. SimSci by Schneider Electric Software; SimSci, PRO/II: Lake Forest, CA, USA, 2017.

9. Couper, J.R. Process Engineering Economics; Marcel Dekker, Inc.: New York, NY, USA, 2003.

10. Won, W.; Maravelias, C.T. Thermal fractionation and catalytic upgrading of lignocellulosic biomass to biofuels: Process synthesis and analysis. Renew. Energy 2017, 114, 357-366. [CrossRef]

11. Walas, S.M. Chemical Process Equipment: Selection and Design; Butterworth: Wobum, MA, USA, 1988.

12. Chemical Engineering Plant Cost Index (CEPCI) 2017. Available online: www.chemengonline.com/pci (accessed on 29 January 2018).

13. Won, W.; Motagamwala, A.H.; Dumesic, J.A.; Maravelias, C.T. A co-solvent hydrolysis strategy for the production of biofuels: Process synthesis and technoeconomic analysis. React. Chem. Eng. 2017, 2, 397-405. [CrossRef]

14. Leistritz, F.L.; Hodur, N.M.; Senechal, D.M.; Stowers, M.D.; McCalla, D.; Saffron, C.M. Biorefineries using agricultural residue feedstock in the great plains. In Proceedings of the Western Regional Science Association Annual Meeting, Newport Beach, CA, USA, 21-24 February 2007.

15. Song, D.; Yoon, Y.G.; Lee, C.J. Techno-economic evaluation of the 2,3-butanediol dehydration process using a hydroxyapatite-alumina catalyst. Korean J. Chem. Eng. 2018, 35, 2348-2354. [CrossRef]

16. Kwon, S.; Won, W.; Kim, J. A superstructure model of an isolated power supply system using renewable energy: Development and application to Jeju Island, Korea. Renew. Energy 2016, 97, 177-188. [CrossRef]

17. Won, W.; Kwon, H.; Han, J.; Kim, J. Design and operation of renewable energy sources based hydrogen supply system: Technology integration and optimization. Renew. Energy 2017, 103, 226-238. [CrossRef]

18. Han, S.; Won, W.; Kim, J. Scenario-based approach for design and comparatively analysis of conventional and renewable energy systems. Energy 2017, 129, 86-100. [CrossRef]

19. International Standardization Organization (ISO). 14040: Environmental Management-Life Cycle Assessment-Principles and Framework; British Standards Institution: London, UK, 2006.

20. Von der Assen, N.; Voll, P.; Peters, M.; Bardow, A. Life cycle assessment of $\mathrm{CO}_{2}$ capture and utilization: A tutorial review. Chem. Soc. Rev. 2014, 43, 7982-7994. [CrossRef] [PubMed]

21. Von der Assen, N.; Bardow, A. Life cycle assessment of polyols for polyurethane production using $\mathrm{CO}_{2}$ as feedstock: Insights from an industrial case study. Green Chem. 2014, 16, 3272-3280. [CrossRef]

22. Artz, J.; Müller, T.E.; Thenert, K.; Kleinekorte, J.; Meys, R.; Sternberg, A.; Leitner, W. Sustainable conversion of carbon dioxide: An integrated review of catalysis and life cycle assessment. Chem. Rev. 2017, 118, 434-504. [CrossRef] [PubMed]

(C) 2019 by the authors. Licensee MDPI, Basel, Switzerland. This article is an open access article distributed under the terms and conditions of the Creative Commons Attribution (CC BY) license (http://creativecommons.org/licenses/by/4.0/). 